\title{
Efeito da adubação orgânica e mineral no crescimento de plantas de orégano cultivadas em ambiente protegido
}

\section{Effect of organic and mineral fertilizers in growth of oregano's plants grown in protected environment}

\author{
Vanuze Costa de Oliveira ${ }^{1}$, Anacleto Ranulfo dos Santos ${ }^{2}$, Girlene Santos de Souza ${ }^{3}$
}

Resumo: O orégano é uma das plantas aromáticas e condimentares mais utilizadas no Brasil e a maior parte do produto consumido é proveniente de importação, mesmo o País apresentando condições de clima e solo favoráveis para o cultivo desta erva. Este trabalho teve como objetivo avaliar o efeito da adubação orgânica e mineral em plantas de orégano cultivado sob malha colorida. Foi adotado o esquema fatorial 4x4 (sendo quatro ambientes de luz modificada e quatro fontes de nutrientes: Latossolo Amarelo, esterco bovino, composto orgânico e NPK), adotou-se o DIC com seis repetições. Avaliaram-se as seguintes características de crescimento: altura das plantas, produção de massa seca e razão de peso foliar. Constatou-se que as plantas adubadas com esterco bovino obtiveram maior altura e maior produção de massa seca; e as plantas cultivadas no ambiente protegido pela malha azul tiveram maior altura, massa seca de raiz e massa seca total.

Palavras-chaves: fertilidade do solo, nutrição de plantas, plantas aromáticas, Origanum vulgare.

\begin{abstract}
The oregano is one of aromatic and spice plants most used in Brazil and the more part of the to consumption comes from imports, even the Country presenting favorable conditions of soil and climate for growing this herb. This study aimed to evaluate the effect of organic and mineral fertilizer in oregano plants cultivated under colored mesh. It was adopted a factorial scheme 4x4 (four modified light environments and four sources of nutrients: Oxisol, bovine manure, organic compound and NPK), was adopted the DIC with six replications. We evaluated the following growth characteristics: plant height, dry matter yield and leaf weight ratio. We evaluated the following growth characteristics: plant height, dry matter yield and leaf weight ratio. It was found that plants fertilized with bovine manure had presented greater height and higher production of dry matter; and plants grown under blue net had greater height, root dry weight and total dry mass.
\end{abstract}

Key words: soil fertility, nutrition of plants, aromatic plants, Origanum vulgare.

\footnotetext{
*Autor para correspondência

Recebido para publicação em 04/02/2015; aprovado em 08/05/2015

${ }^{1}$ Bacharela em Agroecologia, MSc. Solos e Qualidade de Ecossistemas; Doutoranda em Ciência do Solo - UFLA/DCS - Universidade Federal de Lavras, Lavras-MG. E-mail: vanuzeoliveira@ hotmail.com

${ }^{2}$ Eng. Agr. DSc., Professor do Centro de Ciências Agrárias, Ambientais e Biológicas - UFRB/CCAAB - Universidade Federal do Recôncavo da Bahia, Cruz das Almas-BA. E-mail: anacleto@ufrb.edu.br

${ }^{3}$ Eng. Agr. DSc., Professora do Centro de Ciências Agrárias, Ambientais e Biológicas - UFRB/CCAAB - Universidade Federal do Recôncavo da Bahia, Cruz das Almas-BA. E-mail: girlene@ufrb.edu.br
} 


\section{INTRODUÇÃO}

O orégano (Origanum vulgare L.) é uma planta aromática e medicinal perene, pertencente à família Lamiaceae e apresenta boa adaptação a vários ambientes, dentre eles, aqueles mais secos. Isso favorece seu uso e cultivo em diversas partes do Brasil e do mundo.

Este é um dos condimentos mais utilizados na culinária brasileira, principalmente no preparo de massas e carnes (CORRÊA et al., 2010). No entanto, apesar de ser um produto de grande uso no Brasil e o País apresentar características edafoclimáticas favoráveis ao seu cultivo, no período de 2008 até 2011 houve a importação de cerca de 130 t da planta para uso na medicina, perfumaria, dentre outros (CARTAXO et al., 2012). Estes autores ainda afirmaram que dentre os produtos de horticultura e floricultura importados, o orégano está em terceiro lugar tanto em termos de importação, quanto de custos, ficando atrás apenas de sementes de cominho e mudas de orquídeas.

Assim sendo, nota-se a necessidade de estudos relacionados à melhoria dos ambientes de cultivo, bem como a melhor fonte para adubação destas plantas, já que a nutrição mineral das plantas e as modificações ambientais são fatores que exercem grande influência no crescimento e desenvolvimento do vegetal (SEIXAS et al., 2013). A luz é o fator controlador dos processos vitais das plantas e, desta maneira, quando plantas são cultivadas em ambientes de luz modificada podem apresentar distintas respostas, seja na produção de massa seca, produção de óleo essencial, ou até mesmo modificações na anatomia de suas folhas (SOUZA et al., 2011; COSTA et al., 2012; SILVA JÚNIOR et al., 2012; CHAGAS et al., 2013).

Outro importante ponto a se considerar é a adubação, que é considerado o insumo que tem contribuição na maximização da produção e produtividade. Ao utilizar adubação orgânica, vários pesquisadores detectaram aumento na produção de massa seca e aumento no rendimento de óleo essencial de plantas medicinais da família Lamiaceae (LEONANZUETO et al., 2011; CHAGAS et al., 2013; CORRÊA et al., 2009). Isso pode estar relacionado à melhoria que o adubo orgânico ocasiona nas propriedades físicas, químicas e biológicas do solo.

Neste contexto, pesquisas têm sido realizadas com o objetivo de avaliar o comportamento de plantas aromáticas, medicinais, dentre outras, em diferentes condições de luminosidade e fertilidade do solo.

Diante disto, objetivou-se avaliar influencia da adubação orgânica e mineral no crescimento de plantas de orégano crescidas em ambiente de luz modificada com o uso de malhas coloridas.

\section{MATERIAL E MÉTODOS}

O trabalho foi realizado no campo experimental da Universidade Federal do Recôncavo da Bahia (UFRB), no município de Cruz das Almas-BA, o qual está localizado geograficamente a $12^{\circ} 40^{\prime} 19^{\prime \prime} \mathrm{S}$ e $39^{\circ} 06^{\prime} 22^{\prime \prime} \mathrm{W}$ com altitude de $225 \mathrm{~m}$.

Utilizou-se Latossolo Amarelo com as seguintes características químicas na camada de 0 a $20 \mathrm{~cm}$ : pH (em $\left.\mathrm{H}_{2} \mathrm{O}\right)=6,65 ; 0,0 \mathrm{Cmol}_{\mathrm{c}} \mathrm{dm}^{-3}$ de $\mathrm{Al}^{+3} ; 12,5 \mathrm{Cmol}_{\mathrm{c}} \mathrm{dm}^{-3} \mathrm{de}$ Ca+Mg; P- Mehlich 18,0 $\mathrm{mg} \mathrm{dm}^{-3} ; 55,0 \mathrm{mg} \mathrm{dm}^{-3}$ de K ; Matéria orgânica $=21,00 \% ; \mathrm{V}(\%)=94,91$; Soma de bases $=$ $76,50\left(\mathrm{Cmolc} \mathrm{dm}^{-3}\right) ; \mathrm{CTC}=13,56\left(\mathrm{Cmolc} \mathrm{dm}^{-3}\right)$.
$\mathrm{O}$ esterco bovino apresentou as seguintes características

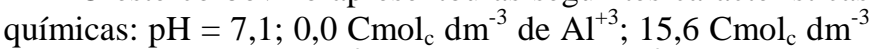
de Ca+Mg; 90,0 mg dm ${ }^{-3}$ de P; 780,0 $\mathrm{mg} \mathrm{dm}^{-3}$ de K; Matéria orgânica $=42,30 \%$. E a composição do composto orgânico

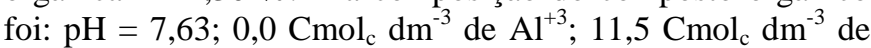
$\mathrm{Ca}+\mathrm{Mg} ; 77,0 \mathrm{mg} \mathrm{dm}^{-3}$ de P; 470,0 $\mathrm{mg} \mathrm{dm}^{-3}$ de K; Matéria orgânica $=39,10 \%$. A formulação do NPK foi 10:10:10.

Foram utilizadas plantas de orégano cujas mudas foram produzidas a partir de uma planta matriz com 60 dias (ciclo de 90 dias), proveniente de um horto localizado na zona rural do município de Cruz das Almas-BA, propagadas de forma convencional por meio de estaquia. Durante todo o período do experimento foi realizada irrigação manual mantendo o solo com umidade próxima a capacidade de campo.

Foi adotado o fatorial $4 \times 4$ (sendo o primeiro fator referente à fontes nutricionais: esterco bovino, composto orgânico, NPK e o Latossolo Amarelo sem o acréscimo de qualquer fonte nutricional; e o segundo fator relacionado ao ambiente de luz modificado com o uso de malhas coloridas nas cores azul, cinza e vermelha; além da testemunha absoluta cultivada a pleno sol).

Utilizou-se o delineamento inteiramente casualizado com seis repetições. Para os adubos orgânicos (esterco bovino e composto orgânico), foi utilizado o equivalente a $90 \mathrm{t} \mathrm{ha}^{-1}$, e as doses de N, P e K foram: 120, 80 e $100 \mathrm{~kg} \mathrm{ha}^{-1}$, respectivamente. As plantas foram cultivadas em vasos com capacidade para $3 \mathrm{dm}^{3}$.

Após 90 dias sob os tratamentos foram medidas as alturas das plantas e, com a desidratação do material em estufa de $65^{\circ} \mathrm{C}$ foi possível determinar a massa seca total (MST), massa seca das folhas (MSF), massa seca da raiz (MSR) e razão de peso foliar (RPF). Estes parâmetros de crescimento foram determinados conforme Peixoto et al. (2011).

Os dados foram submetidos à análise de variância e aplicou-se o teste de Tukey a $5 \%$ de probabilidade.

\section{RESULTADOS E DISCUSSÃO}

Não houve diferença significativa para a interação dos fatores ambiente de luz e adubação; assim sendo, os fatores foram avaliados de forma isolada.

Em relação à adubação, percebe-se que o uso de distintos adubos contribuíram para o aumento da altura das plantas de orégano e da formação de massa seca da raiz e total (Figura 1). Para a altura das plantas (Figura 1A) aquelas que não receberam adubação foram as que apresentaram menor valor para a altura, o que também ocorreu com a formação de massa seca da raiz e massa seca total (Figura 1B), mostrando a importância da adubação para a melhoria das características de crescimento de plantas de orégano. O que também foi constatado por Maia et al. (2008) ao trabalharem com plantas de bamburral (Hyptis suaveolens (L.) Poit.) com adubação orgânica em mineral.

Esses maiores valores para a altura e massa seca nas plantas que receberam alguma adubação podem ser relacionados ao aumento na fertilidade do solo, através do acréscimo de nutrientes por meio da adubação (SALES et al., 2009). Além disso, Chagas et al. (2011) afirmam que em solos mais adubados, há maior acúmulo de biomassa, o que pode significar que níveis mais elevados de nutrientes proporcionados pela adubação têm efeitos positivos no crescimento e no desenvolvimento das plantas. 
Figura 1. Altura (A) e massa seca (B) das plantas de Origanum vulgare L. cultivadas com distintos adubos (SL: Latossolo; CO: composto orgânico; NPK: adubação mineral; EB: esterco bovino). Cruz das Almas-BA, 2014. Colunas seguidas pela mesma letra, para cada variável, não difere estatisticamente a $5 \%$ de probabilidade pelo teste de Tukey.

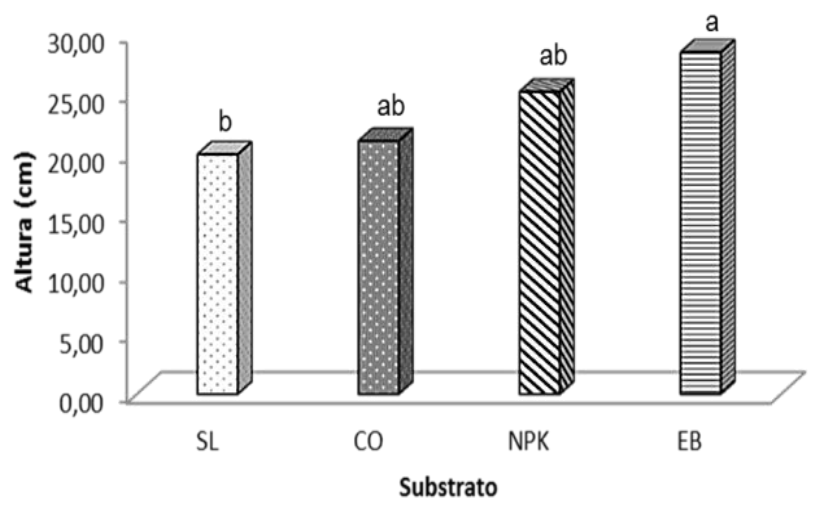

A

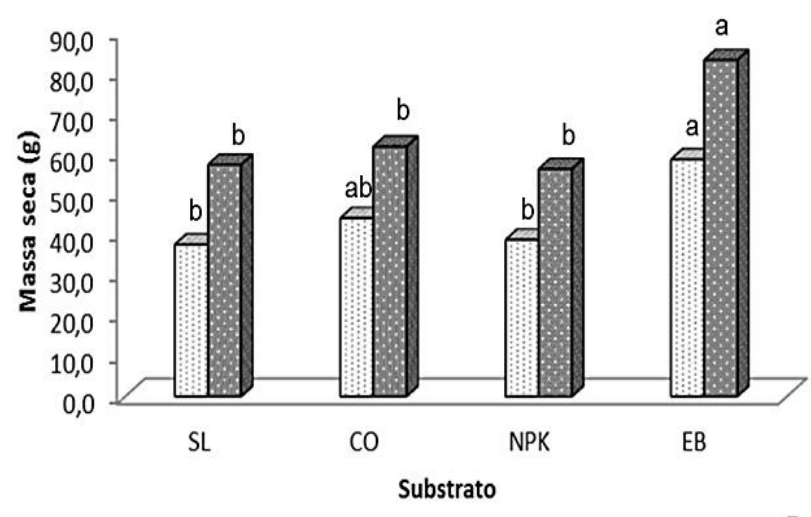

B

口SL I GCO שNPK 目EB

DMRS DMST

O valor positivo para as plantas cultivadas com esterco bovino pode estar relacionado ao fato de que, ao se adicionar adubos orgânicos ao solo, na maioria das vezes, o resultado é a resposta positiva na produção vegetal, favorecendo o crescimento vegetativo.

Ao trabalharem com plantas de Ocimum basilicum L., Luz et al. (2014) mostraram que o uso de substratos não proporcionou diferenças estatísticas significativas no aumento de massa seca, porém em plantas de "mil-folhas", Ferraz et al. (2014) comprovaram que a presença do esterco bovino favoreceu o acúmulo de massa seca da parte aérea.

Para a formação de massa seca total, o esterco bovino proporcionou às plantas de orégano $83 \mathrm{~g}$, em média. O equivalente a $32 \%$ de aumento desta variável, quando comparada às plantas que foram adubadas com NPK, que proporcionou formação média de massa seca total de $56 \mathrm{~g}$. Para a massa seca de raízes a diferença foi de $36 \%$ ao se comparar os valores obtidos nas plantas que foram adubadas com esterco bovino (58 g) e as plantas que foram cultivadas apenas no Latossolo Amarelo, sem o uso de qualquer adubo (37 g).

Também trabalhando com plantas de orégano, Corrêa et al. (2010) constataram que a adubação orgânica tem influência significativa na produção de massa seca desta cultura. O mesmo também foi constatado por Souza et al. (2010), ao trabalharem adubação orgânica em plantas de Lippia citriodora Kunth. Esses resultados podem estar ligados ao fornecimento de nutrientes por parte dos adubos orgânicos para os vegetais, já que, a maior parte destes se caracteriza pela presença de grandes quantidades de nutrientes, em especial, de macronutrientes. Além disso, as respostas positivas das plantas de orégano podem ser justificadas porque esta cultura possui boa aceitação à adubação orgânica, assim como a maioria das plantas, independente da família botânica a que pertençam.

Para a quantidade de massa seca em plantas de "milfolhas", Ferraz et al. (2014) encontraram resposta linear quando foram usadas doses crescentes de adubos orgânicos. Ou seja, à medida que a dose do adubo orgânico aumentou, houve maior incremento de massa seca nesta planta.
Em relação aos ambientes de luz modificados pelo uso de malhas coloridas, observa-se na Figura 2 que o uso de malhas coloridas contribuiu com alguns parâmetros de crescimento das plantas de orégano. Dentre estes, estão altura, massa seca de raiz, massa seca total e a razão de peso foliar (Figura 2).

Para a altura das plantas, aquelas cultivadas nos ambientes protegidos pelas malhas apresentaram maiores valores; no entanto, dentre as condições de luz, não houve diferença estatística, para as plantas que cresceram sob malha azul, vermelha e cinza, possibilitando afirmar que a altura das plantas de orégano são mais influenciadas pela intensidade do que pela qualidade da luz (Figura 2A). O ambiente de luz pleno sol fez com que as plantas obtivessem menores valores para o parâmetro altura $(14 \mathrm{~cm})$.

Ao trabalhar com Ocimum gratissimum, Fernandes (2012) constatou que as plantas crescidas com sombreamento apresentaram maior altura; o que também foi constatado em plantas de manjericão (PAULUS et al., 2016). Isso pode ser explicado porque as plantas apresentam distintas resposta a intensidade de radiação luminosa, sendo que a altura é um dos estímulos de resposta mais rápidos ao sombreamento (MORELLI; ROBERTTI, 2000). E, de acordo com algumas pesquisas, espécies medicinais apresentam maior crescimento em altura nas plantas que recebem algum sombreamento (SALES et al., 2009; LUZ et al., 2014; PAULUS et al., 2016).

Plantas crescidas sob malha azul, apresentaram maiores valores para a altura, embora não diferindo estatisticamente das demais cultivadas sob ambiente protegido, isso porque a malha de cor azul transmite banda larga em $470 \mathrm{~nm}$, comprimento de onda em que ocorre o maior estado de excitação da clorofila, devido aos altos estados de excitação energética que a luz azul propicia (OLIVEIRA, 2014); isso pode explicar o fato das plantas crescidas sob malha azul terem apresentado maiores alturas. Embora não diferindo estatisticamente das cultivadas sob malha vermelha e na malha cinza. 
Figura 2. Altura (A); massa da raiz seca (B); massa seca total (C) e razão de peso foliar (D) de plantas de Origanum vulgare L. cultivadas sob malhas coloridas e a pleno sol (SOL: pleno sol; CZ: malha cinza; VM: malha vermelha; AZ: malha azul). Cruz das Almas-BA, 2014. Colunas seguidas pela mesma letra, para cada variável, não difere estatisticamente a $5 \%$ de probabilidade pelo teste de Tukey.

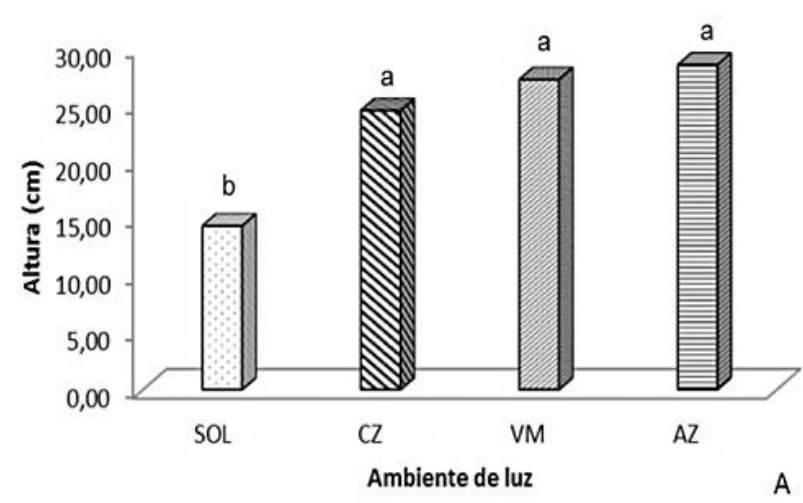

口SOL 『CZ ロVM GAZ

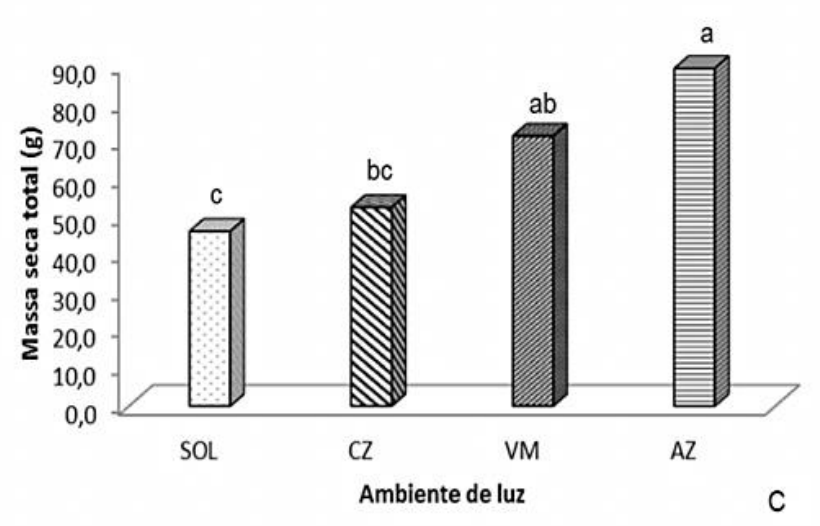

口SOL $\square C Z$ 『M GAZ

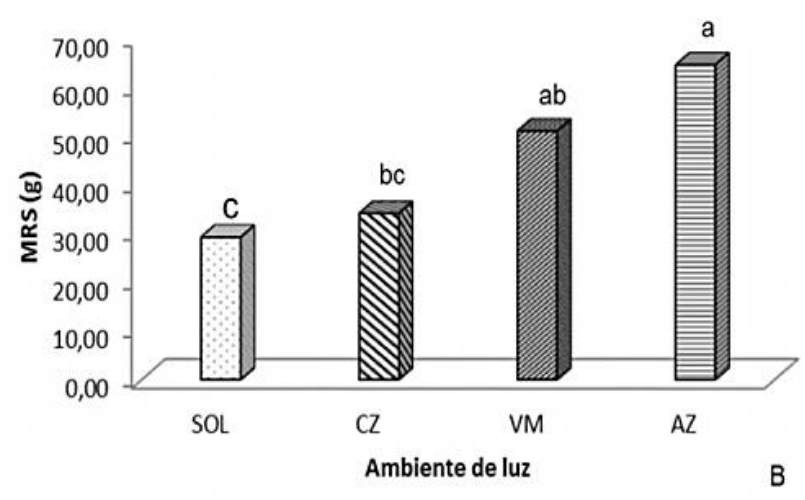

口SOL $\square C Z$ QVM GAZ

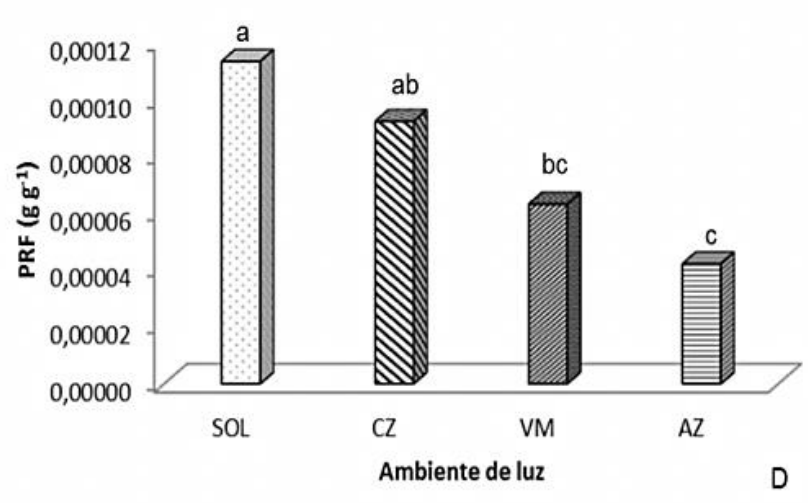

口SOL $\square C Z$ @M GAZ
As plantas crescidas sob malha azul proporcionaram aumento na produção de massa seca das folhas (Tabela 1), isso pode explicar o fato de as raízes de tais plantas apresentarem maior massa seca, quando comparadas àquelas cultivadas sob outros ambientes de luz; já que as folhas são o centro de produção de massa e as demais partes da planta dependem da exportação de fotoassimilados da folha, com isso, o sistema radicular foi beneficiado (Figura 2B). A mesma relação pode ser feita com o aumento de massa seca total nas plantas que cresceram sob malha azul. Neste ambiente, as plantas absorveram de forma mais eficiente as ondas de luz, o que fez com que apresentassem valores mais elevados do que as plantas cultivadas em outros ambientes de luz.

Em plantas de Melissa officinalis L., Meira et al. (2012) mostraram que sombreamento de $50 \%$ proporcionou o aumento na produção de massa seca.

Diferentes plantas obtêm distintos comportamentos quando submetidas às diversas condições ambientais. $\mathrm{O}$ que varia de espécie para espécie, como constatado para a cultura da hortelã-japonesa, que, ao ser cultivada sob malhas coloridas, detectou-se que as plantas que estavam em pleno sol apresentaram maior formação de massa seca total (CHAGAS et al. 2013). No entanto, plantas de Melissa officinallis (BRANT et al., 2009), e plantas de guaco (SOUZA et al., 2011) acumularam mais matéria seca do que as plantas cultivadas em ambiente protegido.
As plantas crescidas sob pleno sol apresentaram maior razão de peso foliar e menor translocação de material das folhas para as demais partes da planta (Figura 2D), quando comparada aos outros tratamentos, o que explica o baixo acúmulo de massa seca de raiz (Figura 2B). A razão de peso foliar (RPF) expressa a quantidade de massa não transferida das folhas para outras partes da planta (PEIXOTO et al., 2011).

Situação distinta foi encontrada por Chagas et al. (2013) em plantas de hortelã-japonesa. Nesta pesquisa, eles constataram que o acúmulo de massa seca pelas raízes se deu em plantas cultivadas em pleno sol. Isso pode ser explicado porque as respostas quanto à intensidade luminosa e, em especial, o uso das malhas, será diferente para cada espécie vegetal, mesmo pertencendo a mesma família botânica, o que ocorre com as plantas de hortelã-japonesa e o orégano, ambas pertencentes à família Lamiaceae.

Em plantas de orégano cultivadas sob malhas coloridas, Corrêa et al. (2012) obtiveram maior RPF nas plantas cultivadas sob malha azul, o que eles relacionaram à maior retenção de fotoassimilados nas folhas destas plantas em relação às cultivadas a pleno sol e complementaram afirmando que a maior exportação de nutrientes para as demais partes da planta foi obtida em plantas cultivadas em pleno sol. 


\section{CONCLUSÕES}

O uso de adubos orgânicos favorece o aumento na altura das plantas e no incremento de massa seca de raiz e total em plantas de orégano

A malha azul favorece o aumento na altura das plantas, massa seca de raiz e massa seca total. No entanto, as plantas crescidas sob esta malha, apresentaram menor razão de peso foliar.

\section{AGRADECIMENTOS}

À Capes e FAPESB pelo apoio financeiro e concessão de bolsa de estudo.

\section{REFERÊNCIAS BIBLIOGRÁFICAS}

BRANT, R.S.; PINTO, J.E.B.P.; ROSAL, L.F.; ALBUQUERQUE, C.J.B.; FERRI, P.H.; CORREA. Crescimento, teor e composição do óleo essencial de melissa cultivada sob malhas fotoconversoras. Ciência Rural, v.39, n.5, p.1401-1407, 2009.

CARTAXO, E.A.; LEITE, J.C.F.; LIMA, L.D. Horticultura e Floricultura no Nordeste. Caderno de Estatísticas Setoriais. Banco do Nordeste: Central de Informações Econômicas, Sociais e Tecnológicas. Escritório Técnico e Estudos Econômicos do Nordeste - ETENE, 2012.

CHAGAS, J.H.; PINTO, J.E.B.P.; BERTOLUCCI, S.K.V.; SANTOS, F.M.; BOTREL, P.P.; PINTO, L.B.B. Produção da hortelã-japonesa em função da adubação orgânica no plantio e em cobertura. Horticultura Brasileira, v.29, p.412-417, 2011.

CHAGAS, J.H.; PINTO, J.E.B.P.; BERTOLUCCI, S. K.V.; COSTA, A. G.; JESUS, H. C. R.; ALVES, P. B. 2013. Produção, teor e composição química do óleo essencial de hortelã-japonesa cultivada sob malhas fotoconversoras. Horticultura Brasileira, v.31, n.2, p.297-303, 2013.

CORRÊA, R.M.; PINTO, J.E.B.P.; REIS, E.S.; COSTA, L.C.B.; ALVES, P.B.; NICULAN, E.S.; BRANT, R.S. Adubação orgânica na produção de biomassa de plantas, teor e qualidade de óleo essencial de orégano (Origanum vulgare L.) em cultivo protegido. Revista Brasileira de Plantas Medicinais, Botucatu, v.12, n.1, p.80-89, 2010.

CORRÊA, R.M.; PINTO, J.E.B.; REIS, E.S.; MOREIRA, C.M. Crescimento de plantas, teor e qualidade de óleo essencial de folhas de orégano sob malhas coloridas. Gl. Sci. Technol., v.5, n.1, p.11-22, 2012.

COSTA, A.G.; CHAGAS, J.H.; PINTO, J.E.B.P.; BERTOLUCCI, S.K.V. Crescimento vegetativo e produção de óleo essencial de hortelã-pimenta cultivada sob malhas. Pesquisa Agropecuária Brasileira, v.47, n.4, p.534-540, 2012.

FERNANDES, V.F. Crescimento, produção do óleo essencial e anatomia foliar de Ocimum gratissimum
L. (Lamiaceae) em diferentes níveis de radiação luminosa. 2012. 78f. Dissertação (Mestrado em Produção vegetal). Universidade Estadual de Santa Cruz-UESC, Ilhéus-BA. 2012.

FERRAZ, E.O.; BERTOLUCCI, S.K.V.; PINTO, J.E.B.P.; BRAGA, A.F.; COSTA, A.G. Organic systems in the growth and essential-oil production of the yarrow. Rev. Ciênc. Agronômica, v.45, n.1, p.111-119, 2014.

LEON-ANZUETO, E.; ABUD-ARCHILA, M.; DENDOOVEN, L.; VENTURACANSECO, L. M.C.; GUTIÉRREZ-MICELI, F.A. Effect of vermicompost, worm-bed leachate and arbuscular mycorrizal fungi on lemongrass (Cymbopogon citratus (DC) Stapf.) growth and composition of its essential oil. Electron. J. Biotechnol, v.14, n.6, p. 5-5, 2011.

LUZ, J.M.Q.; RESENDE, R.F.; SILVA, S.M.; SANTANA, D.G.; CAMILO, J.S.; BLANK, A.F.; HABER, L.L. Produção de óleo essencial de Ocimum basilicum L. em diferentes épocas, sistemas de cultivo e adubações. Boletín Latinoamericano y del Caribe de Plantas Medicinales y Aromáticas, v.13, n.1, p.69-80, 2014.

MAIA, S.S.; PINTO, J.E.B.P.; SILVA, F.N.; OLIVEIRA, C. Influência da adubação orgânica e mineral no cultivo do bamburral (Hyptis suaveolens (L.) Poit.) (Lamiaceae) Revista Brasileira de Ciências Agrárias, v.3, n.4, p.327-331, 2008.

MEIRA, M.R; MARTINS, E.R.; MANGANOTTI, S.A. Crescimento, produção de fitomassa e teor de óleo essencial de melissa (Melissa officinalis L.) sob diferentes níveis de sombreamento. Rev. Bras. Pl. Med., v.14, n.2, p. 352-357, 2012.

MORELLI, G.; RUBERTI, I. Shade avoidance responses. Driving auxin along lateral routes. Plant Physiology, v.122, p.621-626, 2000.

PAULUS, D.; VALMORBIDA, R.; FERREIRA, S.B.; ZORZZI, I.C.; NAVA, G.A. Biomassa e composição do óleo essencial de manjericão cultivado sob malhas fotoconversoras e colhido em diferentes épocas. Horticultura Brasileira, v.34, n.1, p.46-53, 2016.

OLIVEIRA, V.C. Adubação orgânica e mineral em plantas de orégano cultivadas sob malhas fotoconversoras em Latossolo Amarelo. 2014. 92f. Dissertação (Mestrado em Solos e Qualidade de Ecossistemas). Universidade Federal do Recôncavo da Bahia - UFRB, Cruz das Almas-BA. 2014.

PEIXOTO, C.P., CRUZ, T.V., PEIXOTO, M.F.S.P. Análise quantitativa do crescimento de plantas: Conceitos e prática. ENCICLOPÉDIA BIOSFERA, Centro Científico Conhecer, v.7, p.51-76, 2011.

SALES, J.F.; PINTO, J.E.B.P.; FERRI, P.H.; SILVA, F.G.; OLIVEIRA, C.B.A.; BOTREL, P.P. Influencia do nível de irradiância no crescimento, produção e composição 
química do óleo essencial de hortelã-do-campo (Hyptis marrubioides Epl.). Semina. Ciências Agrárias, v.30, p.379-386, 2009.

SEIXAS, P.T.L.; CASTRO, H.G.; CARDOSO, D.P.; CHAGAS JÚNIOR, A.F.; NASCIMENTO, I.R.; BARBOSA, L.C.A. Efeito da adubação mineral na produção de biomassa e no teor e composição do óleo essencial do capim-citronela. Bioscience Journal, v. 29, n. 04, p. 852-858, 2013.

SILVA JÚNIOR, J.M.; CASTRO, E.M.; RODRIGUES, M.; PASQUAL, M.; BERTOLUCCI, S.K.V. Variações anatômicas de Laelia purpurata var. cárnea cultivada in vitro sob diferentes intensidades e qualidade spectral de luz. Ciência Rural, v.42, n.3, p.480-486, 2012.
SOUZA, M.F.; SOUZA JUNIOR, I.T.; GOMES, P.A.; FERNANDES, L.A.; MARTINS, E.R.; COSTA, C.A.; SAMPAIO, R.A. Calagem e adubação orgânica na produção de biomassa e óleo essencial em Lippia citriodora Kunth. Rev. Bras. Pl. Med., v.12, n.4, p.401$405,2010$.

SOUZA, G.S.; CASTRO, E.M.; SOARES, A.M.; PINTO, J.E.B.P.; RESENDE, M.G.; BERTOLUCCI, S.K.V. Crescimento, teor de óleo essencial conteúdo de cumarina de plantas jovens de guaco (Mikania glomerata Sprengel) cultivadas sob malhas coloridas. Revista Biotemas, v.24, p.1-11, 2011. 